\title{
Analysis of demand for children in Madhya Pradesh and its implication on population stabilization
}

\author{
Monorisha Mukhopadhyay \\ ${ }^{1}$ (Senior Researcher, CORD, New Delhi)
}

\begin{abstract}
With socio-economic development motivation for fertility control is also generated, as concept of ideal family size among couple starts varying. The demand for an additional child thus subsequently depends on couple's notion of ideal family size. In this study those couples were considered who at least have one living child. The broad objectives of the study were to see how the demand for additional child changes with one, two, three and four living children respectively; the transition of socio-economic factors that determine the progression of demand and did the demand for children decline in Madhya Pradesh with the socio-economic development. The key factors taken in the study were educational status of the women, caste, sex composition of the existing children and number of surviving children. The principal dataset used in the study was NFHS-III, 2005-06. The results show that living number of sons and wealth status influence the desire to have more children. The main challenge in future lies in the mitigating the unmet need of the population.
\end{abstract}

Keywords - contraception, demand, Madhya Pradesh, regression, unmet need

\section{INTRODUCTION:}

Madhya Pradesh often called as the heart of India is marred by delirious effects of poverty, hunger, malnutrition, child, infant and maternal mortality. She is one of the largest states of India where almost 40 per cent of the population lives below poverty line [1]. It is a real dichotomy that in spite of abundance of rich natural resources and prosperous land of cultural heritage the population reflected high population growth, high mortality, low literacy and poor quality of life on social and economic parameters vis-a-vie other developed states. This is primarily due to inadequacy in planning and effective distribution of resources. India is one of the pioneering countries to have introduced the Family Planning (FP) programme (an important part of Family Welfare programme) but those schemes unfortunately could not be successfully and effectively implemented because of lack of implementation and will of the executors. This had led to sluggish process of poverty alleviation and had inadvertently created an imbalance between resource and population. This has prompted us to believe that the large population base and rapidly growing population has become "mother" of all problems of our development [2].

There is a need for curtailing the rate of growth of population through effective population programme to get its optimum impact on poverty alleviation. The fertility of the region is supposed to come down with socio-economic development and subsequent application of suitable family planning measures. With socioeconomic development motivation for fertility control is also generated, as concept of ideal family size among couple starts varying. The demand for an additional child thus subsequently depends on couple's notion of ideal family size. The control can be well applied if the population is well informed and contraceptives available are accessible and affordable. This paper will try to trace to see how the demand for additional child changes with one, two, three and four living children respectively, the transition of socio-economic factors that determine the progression of demand and did the demand for children decline in Madhya Pradesh with the socio-economic development. The main challenge will be to see whether the desire is translated into use of contraceptives and change in contraceptive practices.

\section{DATABASE AND METHODOLOGY:}

For the present study, National Family Health survey (NFHS)-3 (2005-2006) [3] data had been used. NFHS-3 covered representative sample of total 124385 ever- married women in the age group 15-49 years. The particular study focused on currently married women in the age group 15-49 years as they were more likely to give births in a union. The key response variables taken in the study were educational status of the women, caste, experience of child loss, number of living children and living standard of the people. In this study those couples were considered who had at least one living child. Because their behaviour are reflective of the acceptance of fertility control, since women with no living child generally will like to have at least one child as voluntary childlessness is conspicuous by its absence. Bivariate analysis like cross tabulation was done to give 
the association of the socio-economic determinants with total number of children ever born. Cross-tabulation of the variables gives the gross effect of the background variables on the level of fertility. Hence, to obtain the net effect of the background variable on desire of additional child multivariate analysis was done. The results were expected to show a fall in fertility levels with socio-economic development. And as the desire for fertility decreases the acceptance of contraceptive methods were likely to increase. The analysis in this study was attempted under three sub-sections- the desire for additional children across socio-economic characteristics, contraceptive usage and estimating an unmet need of the population.

\section{STUDY AREA}

Madhya Pradesh is among the laggard states in terms of fertility indicators and development. TFR in the state is 2.8 (2015) [4] which reduced from 3.4 (2007) [5]. The slow and steady fertility decline in Madhya Pradesh is also characterized by large regional variations. As per Annual Health Survey (2012-13) the Total Fertility Rate (TFR) or an average number of children born to a woman in a reproductive life span was 3.0 in the state. Only Bhopal and Gwalior had TFR below or at replacement level of 2.1. About 60 per cent of the districts of the state (26 out of 45) had TFR of more than and equal to 3. Districts of Panna and Shivpuri had TFR as high as 4.1 and 4 respectively. The state is likely to reach replacement level fertility by 2025 [6]. The disparate population growth can be checked by gauging the demand of children and addressing the unmet need of population control.

\subsection{Fertility Preference}

\section{RESULTS}

The fertility transition from high order births to stopping at low order births is determined by the fertility preference of the population. The fertility preference depends on number of factors like number of living children, sex composition of the living children, notion of ideal family size and desire for more children. In this paper fertility preference of the couple had been determined from desire for having more children. It is apparent that voluntary childlessness is almost uncommon in Indian subcontinent. The level of fertility is thus dependent on the desire of having an additional child after one or more children which can be termed as fertility limiting indicator. In the survey the women had been asked whether they would like to have an additional child. Respondents who said that they want no more children can be considered the ones who limit the fertility. The results show that a woman with no child desire more children, but as parity increases the desire to have children decreases. It is worth noting that there is huge gap between women having one and less living children and women with more than two living children (Fig 1).

Multivariate analysis had been done by parity of women to see effect of various socio- economic factors that guides the desire for having an extra child. Desire for more children was taken as a dependent variable. Here the dependent variable was in a dichotomous form (desire more children, do not desire more children). Hence, logistic regression was done to see how the desire to have more children varied by socioeconomic differentials. In Model 1 women with one living children had been considered. The dependent variable used was desire for more children. Results show that women with one living son were significantly less desirous to have more children than who had no living son (Table 1). On contrary to present literature women who have experienced any child loss were significantly less interested in having another child than women who had experienced no child loss. Women from the higher wealth quartiles were significantly less likely to desire more children than from poor or poorest quartile. Other variables were not significant and hence had not been discussed.

In Model 2 Women with two living children had been considered. Women with one or two living sons and experience of child loss were significantly less desirous (Table 1) of having more children than women with no living children. Women from higher wealth quartile were less desirous of having any child than from poor and poorest quartile. Other variables were not significant and hence had not been discussed. In Model 3, women with three living children were considered. The women with one and more living sons were significantly less likely to desire any more children than who had no living sons. Similarly women in the higher wealth quartile were significantly less likely to desire more children than women in the poor quartiles. In Model 4 only those women were considered who had four living children. The number of living son/sons significantly affects the desire for having more children. More number of living sons a women had, it becomes less likely to desire any more children. Thus it was seen that as the parity increases the number of living sons become the most significant variable. From the analysis it was seen that women living with two children were most critical in ascertaining the demand of another child; though later it became a function of son biasedness.

\subsection{Use of contraception}

The desire to control fertility is put into practice with efficient use of contraception. Eventually, the likelihood of not having an additional child can be ascertained by looking into the contraception usage as marital 
fertility can be lowered by deliberate and conscious effort to space or limit childbearing [7]. Thus, one could see how the desire to control fertility is transformed into practice. Now the challenge lies in the fact that whether women who had no desire were actually practicing family planning measures or not. From the results it was seen that about 24 per cent (Table 2) of women were not practicing any contraceptive measure in spite of having no desire to have any child. Now as had been told earlier contraceptive practice tends to increase with socioeconomic development. Similarly, from the results (Table 3) it can be seen that as the wealth quartile increases acceptance towards the modern method increases. And most of the women in the poor and poorest quartile do not use any method, in spite of having no desire of having any child. The use of contraception varies by residence status where women living in urban areas used modern services and about one-fifth did not use any method. Also, women with no education were more likely to use no methods $(20 \%)$ in comparison to women with high school and above degree (17\%).

\subsection{Components of unmet need}

In general the potential demand of children in the future can be addressed by gauging the unmet need of the population and the current contraception prevalence. It was estimated that reducing unwanted birth will reduce marital fertility to a large extent in most population of Asia [8]. The improved contraceptive practice will have various repercussions like higher use of contraceptives by non-users, increase of more effective methods and reduction in the rate of discontinuation [9]. The family planning programmes thus should effectively address the unmet need of the population because the other half is being already attended. The women in the reproductive age groups can be divided in to various components based on their desire of having an additional child (no need) and desire of no more children (need). Couples who do not want any more additional child were the ones who were in need of contraception. This group constitutes of couples who were using contraceptives and who were not using any contraceptives. The couple who was not using and also does not want any more children represents the group of unmet need. Apart from this there were couples who do wanted children soon and they were the couple who were in no need of contraception. In the study it had been seen that about 20.6 had (Fig 2) of women were still not using contraceptives in spite of the fact that they do not desire any more children. This was making them vulnerable to unwanted and untimely pregnancies. The value slightly differs from Table $2(24 \%)$ because in any population there were women who were sterilized and hence do not need any more control; though infecund women were already kept outside the analysis.

\section{DISCUSSION AND FINDINGS:}

For women with one living children it was seen that most of the dependent variables were not significant. It is the living number of sons and wealth status which were influencing the desire to have more children. Whereas women with two living children it is the living number of sons, wealth status and experience of child loss i.e. affecting the fertility behaviour of the women. In the higher parity with women having three or four children, it was the number of sons that actually determine the desire to have more children. Thus it can be said that women who were having two living children were critical in understanding the demand of children in the next few years. In the analysis it also came out that desire for more number children decreases if a woman experiences a child loss. This is in contrast to the literature [10,11] which highlighted that with experience of child loss the desire to have more children increases. The strong preference of son found in the region which can be corroborated from other study $[12,13]$ will have to be addressed with the programmes enabling women empowerment. The use of contraceptives is also increasing with increase in wealth and education level. This is also supported from the literature [14] where it is said that demand for the children slowly decreases with socioeconomic development as people tends to adopt family planning techniques. The main challenge in future lies in the mitigating the unmet need of the population with measures like identifying the couples with high unmet need and trace the reasons for non-use or discontinuation of contraception. Dissemination of information on various types of birth control methods and increase in access to family planning techniques will have a bearing on bringing down the unwanted births. The role of men in adoption of family control measures is also undeniable. Building efficiency of the grass root workers like Accredited Social Health Activist (ASHA) and Aanganwadi Worker (AWW) will strengthen the last mile connect between the population programme and the community. Proper incentives can be given to ASHA and local volunteers for support to couples to accept and practice FP. Strong communication and message on relationship of large family size with poverty, higher age at marriage, longer birth interval and use of spacing methods should reach out to the couple. The couples should be motivated to avoid births at higher ages so that higher order births can be reduced. Besides, strengthening monitoring and evaluation system of the family planning programme and incorporating the feedback to the programme will work in addressing the unmet need and accelerating the process of population stabilization. 


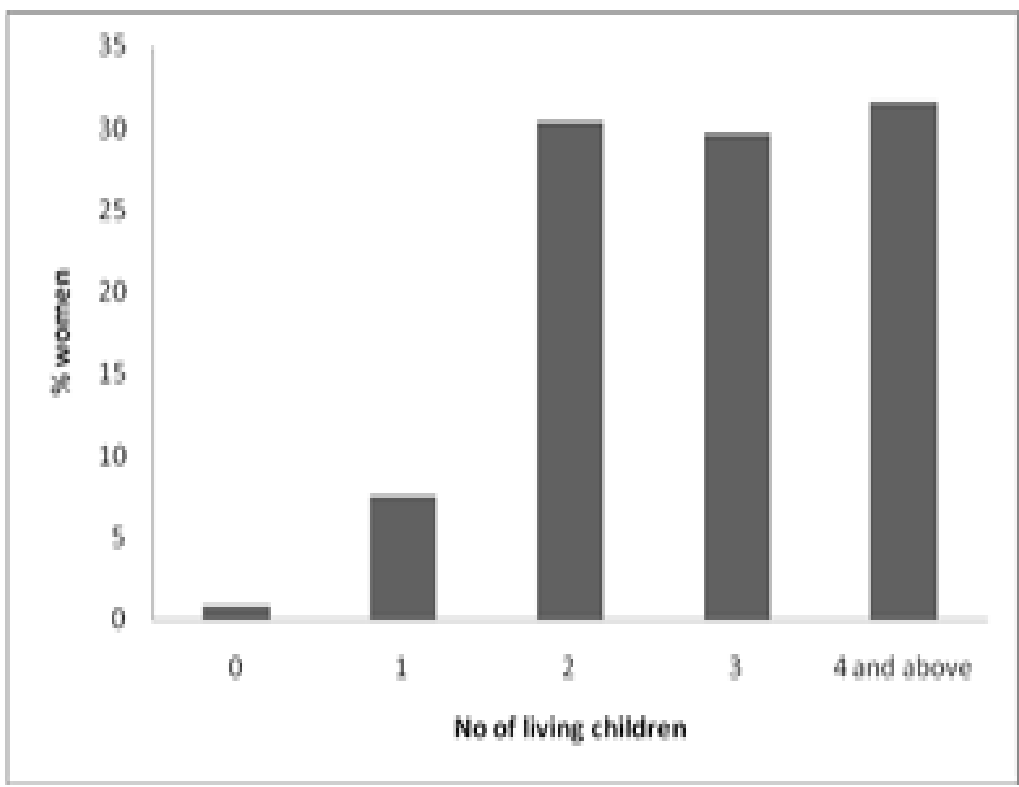

Fig 1: Not Desiring Children by Number of Living Children Madhya Pradesh, NFHS-III, 2005-06

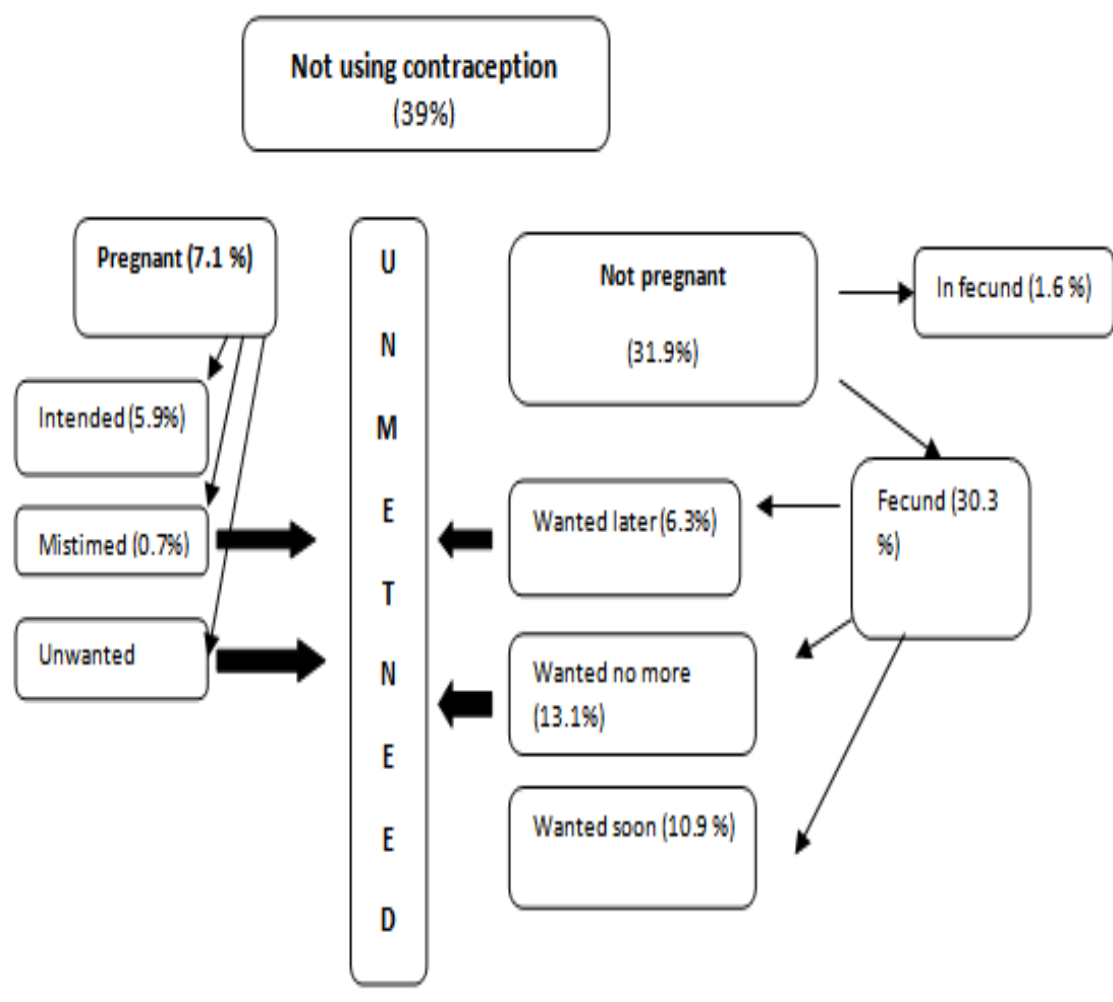

Fig 2: Estimation of Unmet Need in Madhya Pradesh, NFHS-III, 2005-06 
Analysis of demand for children in Madhya Pradesh and its implication on population stabilization

Table 1: Logistic Regression on Desire for More Children to Currently Married Women having Two Living Children across Background Characteristics, Madhya Pradesh, NFHS-III, 2005-06

\begin{tabular}{|c|c|c|c|c|c|c|c|c|c|}
\hline & & \multicolumn{2}{|c|}{\begin{tabular}{|l|} 
Model 1 \\
With 1 living child
\end{tabular}} & \multicolumn{2}{|c|}{ Model 2} & \multicolumn{2}{|l|}{ Model 3} & \multicolumn{2}{|c|}{\begin{tabular}{l|l} 
Model 4 & \\
$\begin{array}{l}\text { With } 4 \\
\text { children }\end{array}$ & living \\
\end{tabular}} \\
\hline & & B & Sig. & B & Sig. & B & Sig. & B & Sig. \\
\hline Residence & Urban ${ }^{\circledR}$ & & & & & & & & \\
\hline \multirow[t]{3}{*}{ Educational level } & No education $\AA$ & & 0.88 & & 0.21 & & 0.27 & & 0.81 \\
\hline & Primary & -0.05 & 0.87 & -0.13 & 0.66 & 0.71 & 0.06 & -0.10 & 0.87 \\
\hline & Secondary & 0.03 & 0.90 & 0.06 & 0.85 & 0.03 & 0.95 & -0.79 & 0.33 \\
\hline \multirow{2}{*}{ Caste } & $\mathrm{OBC}$ & 0.15 & 0.54 & -0.35 & 0.25 & 0.47 & 0.31 & -0.60 & 0.27 \\
\hline & Others & -0.32 & 0.22 & -0.78 & 0.04 & 0.38 & 0.52 & -0.78 & 0.37 \\
\hline \multirow[t]{2}{*}{ Religion } & Hindu ${ }^{\circledR}$ & & & & & & & & \\
\hline & Others & 0.49 & 0.08 & 1.00 & 0.01 & 1.06 & 0.05 & 16.92 & 1.00 \\
\hline \multirow[t]{3}{*}{ No of living sons } & $0 ®$ & & & & 0.00 & & 0.00 & & 0.00 \\
\hline & 1 & -0.71 & 0.00 & -2.73 & 0.00 & -2.93 & 0.00 & -3.42 & 0.00 \\
\hline & 2 & & & -2.76 & 0.00 & -4.62 & 0.00 & -5.57 & 0.00 \\
\hline \multirow[t]{8}{*}{ Wealth Index } & Poorest ${ }^{\circledR}$ & & 0.12 & & 0.00 & & 0.00 & & 0.53 \\
\hline & Poor & -0.10 & 0.76 & 0.33 & 0.33 & -0.25 & 0.51 & -0.13 & 0.79 \\
\hline & Middle & -0.53 & 0.14 & -0.72 & 0.12 & -1.78 & 0.00 & -1.35 & 0.14 \\
\hline & High & -0.91 & 0.02 & -1.06 & 0.02 & -2.02 & 0.00 & -0.74 & 0.41 \\
\hline & Highest & -1.00 & 0.02 & -1.99 & 0.00 & -3.18 & 0.00 & 0.12 & 0.91 \\
\hline & Constant & 1.82 & 0.00 & 1.24 & 0.01 & 0.43 & 0.53 & 0.40 & 0.67 \\
\hline & R Square & & 0.12 & & 0.38 & & 0.40 & & 0.43 \\
\hline & $\mathbf{N}$ & & 719 & & 1256 & & 1168 & & 1224 \\
\hline
\end{tabular}

Source: Estimated from NFHS 3, 2005-06 (indiavidual file) 
Table 2:Bivariate Analysis between desire for children and current use of contraception, Madhya Pradesh, NFHS-III, 2005-06

\begin{tabular}{|l|c|c|c|c|}
\hline & \multicolumn{3}{|c|}{ Current Use of Contraceptive } & \\
\hline & No Method & Traditional & Modern & Total \\
\hline Want no more child & 24.0 & 3.1 & 72.9 & 3651 \\
\hline Wants child & 83.1 & 3.8 & 13.1 & 1185 \\
\hline Total & 38.5 & 3.3 & 58.2 & 4836 \\
\hline
\end{tabular}

Source: Estimated from NFHS 3, 2005-06 (indiavidual file)

Table 3: Use of contraception across background variables by those who don't want any child, Madhya Pradesh, NFHS-III, 2005-06

\begin{tabular}{|c|c|c|c|c|c|}
\hline & & \multicolumn{4}{|c|}{ Type of contraception } \\
\hline & & No method & Traditional & Modern & Total \\
\hline \multirow[t]{6}{*}{ Wealth Status } & Poorest & 33.6 & 2.2 & 64.1 & 845 \\
\hline & Poorer & 24.6 & 1.0 & 74.4 & 589 \\
\hline & Middle & 27.9 & 3.1 & 69.0 & 420 \\
\hline & Richer & 21.6 & 3.0 & 75.4 & 691 \\
\hline & Richest & 16.5 & 4.9 & 78.6 & 1106 \\
\hline & Total & 24.0 & 3.1 & 72.9 & 3651 \\
\hline \multirow[t]{5}{*}{ Education level } & No education & 26.0 & 1.8 & 72.2 & 1784 \\
\hline & Primary & & & & \\
\hline & Secondary & 23.0 & 3.6 & 73.5 & 953 \\
\hline & $\begin{array}{l}\text { Higher Sec and } \\
\text { above }\end{array}$ & 17.7 & 10.1 & 72.2 & 345 \\
\hline & Total & 24.0 & 3.1 & 72.9 & 3651 \\
\hline \multirow[t]{5}{*}{ Caste } & $\mathrm{SC}$ & 26.9 & 2.3 & 70.8 & 657 \\
\hline & ST & 34.3 & 2.2 & 63.5 & 540 \\
\hline & OBC & 22.3 & 2.3 & 75.4 & 1429 \\
\hline & Others & 19.3 & 5.2 & 75.6 & 1023 \\
\hline & Total & 24.0 & 3.1 & 72.9 & 3649 \\
\hline \multirow[t]{3}{*}{$\begin{array}{l}\text { Place } \\
\text { residence }\end{array}$} & Urban & 20.2 & 3.9 & 75.9 & 1869 \\
\hline & Rural & 28.1 & 2.2 & 69.6 & 1782 \\
\hline & Total & 24.0 & 3.1 & 72.9 & 3651 \\
\hline
\end{tabular}

Source: Estimated from NFHS 3, 2005-06 (indiavidual file)

\section{Website}

\section{REFERENCES:}

[1] Population and development: A discourse on family planning in Madhya Pradesh, National Institute of Health and Family welfare, 2014 retrieved from http://www.nihfw.org/Doc/Policy_unit/State\%20Brief\%20MP.pdf

\section{Proceedings Papers}

[2] Talwar, Prem (2016): "Increasing Pace of Population Stabilization for Accelerating Poverty Alleviation" talk delivered as part of monthly series, Lokashraya Foundation, New Delhi

\section{Reports}

[3] International Institute of Population (IIPS) and Macro International. 2007. NFHS-III, 2005-06. Mumbai:India

[4] Register General, Sample Registration System Statistical Report 2007, Report No 1 of 2009. New Delhi: Controller of Publications.

[5] Register General, Sample Registration System Statistical Report 2015, Report No 1 of 2015. New Delhi: Controller of Publications.

[6] Register General, "Population Projection," Ministry of Home Affairs, Office of the Register \& Census Commissioner of India, 2006, India

\section{Proceedings Papers}

[7] Eltigani E., 2001. "Levels and trends of fertility in Oman and Yemen: Workshop on prospects for fertility decline in high fertility countries". Population Division, Department of Economic and Social Affairs. United Nation Secretariat: New York 


\section{Journal Papers}

[8] Westoff, Charles F., "Unwanted fertility in six developing countries". International Family Planning Perspectives 7(2), 1981, 43-52

[9] Westoff, C. F., Lorenzo M. and Noreen G, "The Demographic impact of changes in contraceptive practice in Third world population". Population and Development Review 5(1), 1989, 91-106

[10] Kumar Dinesh et al.,"Effect of sex and survival of infants on fertility in a primitive tribe of Chattisgarh: A factorial analysis". Indian Journal of Preventive Social Medicine. 37(1), 2006, 38-43

[11] Hossain Mian, Phillips James and LeGrand Thomas, "The impact of childhood mortality on fertility in six rural thanas of Bangladesh". Demography 44(4), 2007, 771-784

[12] Kulkarni S and Choe M K. 1998. "Wanted and Unwanted fertility in selected states of India". National Family Health Survey Reports No 6, IIPS and East West Center: Honululu

[13] Patnaik M., "The impact of sex and survival of infants on fertility behaviour: A factorial analysis". Demography India (2), 1987, 221-227

Books

[14] Sharma A K. Fertility and family planning in rural areas (Mittal Publications: Delhi, 1987) 